\title{
COVID-19 pandemic and the quality of couples' sexual relationships
}

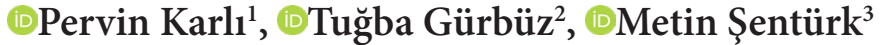 \\ ${ }^{1}$ Amasya University Faculty of Medicine, Gynecology and Obstetric Clinic, Amasya, Turkey \\ ${ }^{2}$ Medistate Hospital, Gynecology and Obstetric Clinic, İstanbul, Turkey \\ ${ }^{3}$ Sabuncuoğlu Şerefeddin Research and Training Hospital, Gynecology and Obstetric Clinic, Amasya, Turkey
}

Cite this article as: Karlı P, Gürbüz T, Şentürk M. COVID-19 pandemic and the quality of couples' sexual relationships. Anatolian Curr Med J 2021; 3(2); 104-108.

\begin{abstract}
Aim: COVID-19 pandemic causes stress between individuals, and this stress can affect the quality of couples' sexual relationships. This study aimed to examine the quality of women's sexual life during the COVID-19 pandemic.

Material and Method: This prospective cross-sectional study was conducted at May-June 2020. 235 sexually active women aged 18 to 51 years participated in this study. The Female Sexual Function Index (FSFI) was used to examine women's sexuality from six different perspectives: desire, arousal, lubrication, orgasm, satisfaction, and pain. Due to quarantine restrictions, questionnaires were emailed to participants.

Results: The participants' age range was 18 to 51 , with an average of $29.6 \pm 6.08$ years. The total FSFI score with a minimum of 1 and a maximum of 26.75 had an average of $18.12 \pm 6.23$. Since the cut-off value for female sexual dysfunction is 26.0 , it can be concluded that, on average, participants had poor function and quality of sexual intercourse in the previous four weeks during the lockdown. The values of the FSFI score were significantly different according to the age of the woman ( $p$-value=0.003), the age of the man ( $p$-value $=0.005)$, and duration of marriage ( $\mathrm{p}$-value $=0.006)$. The woman's age (Sig. $=0.008)$, the man's age $($ Sig. $=0.004)$, and duration of marriage (Sig. $=0.02)$ had a significant and negative correlation with the total FSFI score.

Conclusion: This study showed that the COVID-19 pandemic and lockdown reduced women's sex life quality. Our results also show that the older women and men are, the lower their sexual satisfaction will be, which may be due to the higher risk of COVID-19 for the elderly.
\end{abstract}

Keywords: COVID-19, FSFI, sexual quality of life, pandemic, lockdown

\section{INTRODUCTION}

The outbreak of COVID-19 was reported in late 2019 in Wuhan, China. With a high prevalence rate of fewer than four months, it affected almost every country in the world, with the World Health Organization declaring it a pantdemic on March 11, 2020 (1,2). This highly contagious viral disease has clinical manifestations such as fever, chills, sore throat, cough, difficulty breathing, nausea, vomiting, and diarrhea (3). As of December 2020, it has infected 77.6 million people worldwide caused 1.71 million deaths.

Psychological consequences such as fear and stress about this disease can be very severe and lead to intense emotions (4). Recent studies in China have also shown that the prevalence of COVID-19 disease is the most important public concern and has posed major challenges to individuals' physical and mental health (5). In general, in the face of a crisis that has targeted public health, people are prone to various psychological problems (3). It was shown that basic parameters such as gender, specific physical symptoms, chronic diseases, and poor health status were significantly associated with a wider range of physical and psychological due to the COVID-19 pandemic, such as more severe stress levels and depression $(1,2,4,5)$.

Sexual desires are an important part of human life that can be affected by mental problems or crises (6,7). In 1998, the classification of female sexual dysfunction (FSD) was introduced by the American Urological Association (8). According to them, FSD is known in the form of impaired desire, sexual arousal, and pain during intercourse, and difficulty or inability to orgasm (9). Epidemiological studies have shown that FSD is a common problem in the community, and $20-25 \%$ of women are affected by it $(10,11)$. 
Despite this high prevalence and recent research, the cause of FSD remains relatively unknown, possibly due to the complexity of its underlying physiological process (12). In addition to low objective measurement tools, there are a significant number of self-completion questionnaires that measure FSD. Among these tools, the Female Sexual Function Index (FSFI) is considered the gold standard for assessing female sexual function and has been translated and validated in more than 30 countries (12-14).

Many studies have focused on the pandemic effect on individuals' physical health. Few studies have been performed on the effects of the COVID-19 pandemic and quarantine conditions on sexual health. Therefore, in this study, it was decided to use the FSFI questionnaire to investigate these conditions' effect on female sexual function.

\section{MATERIAL AND METHOD}

This prospective cross-sectional study was conducted at Amasya University Gynecology and Obstetric Clinic. The study was approved by the Ethical Committee of Amasya University (07/05/2020-5/28) and the Turkish Republic dated 2020-05-07T15-56-23 after approval of the application for work by the Ministry of Health Scientific Research Platform. 235 women who referred to Gynecology and Obstetrics Clinic between May and June 2020 participated in the study. All procedures performed in studies involving human participants were in accordance with the ethical standards of the institutional and/or national research committee and with the 1964 Helsinki Declaration and its later amendments or comparable ethical standards.

Two hundred thirty five sexually active women aged 18 to 51 years participated in this study. Participants under the age of 18, diagnosed with COVID-19, had a history of pre-existing mental illnesses such as personality disorders or depression, and subjects who were taking medications reducing libido for up to three months before the study were excluded from the study. Those who agreed to participate in the study did not have any psychiatric diagnosis before, and did not use any drug that was included in the study. The informed consent was received from all women.

In this study, FSFI was used. This index is a 19-item questionnaire that examines women's sexuality from six different perspectives: desire, arousal, lubrication, orgasm, satisfaction, and pain. This assessment measures the respondent in the last four weeks and has a score range from 2 to 36 . A score of less than 26 indicates sexual dysfunction. Due to quarantine restrictions, questionnaires were emailed to participants.
Information was collected on men and women's age, height, weight, duration of the marriage, pregnancy status, smoking, the emotional status between men and women, and income. The FSFI questionnaire was then presented to the participants to assess their sexual function.

\section{Statistical Analyses}

A Chi-square test was used to examine the significant difference between each of the qualitative variables. For quantitative variables, after examining their abnormality using the Kolmogorov-Smirnov test, the non-parametric equivalent of a one-way ANOVA test, the Kruskal-Wallis test was used. Statistical Package for Social Sciences (SPSS) version 26.0 (SPSS Inc., Chicago, IL, USA) was used to perform analysis.

\section{RESULTS}

The mean age of women participants 29.6 years. The mean age of male participants $32.9 \pm 6.3$ years. Participants ranged in weight from 45 to 120 , with an average of $71 \pm 13.4 \mathrm{~kg}$, and height ranged from 145 to 185 , with an average of $162 \pm 5.6 \mathrm{~cm} .10$ (4.3\%) participants had primary education, $36(15.3 \%)$ had secondary education, $79(33.6 \%)$ had high school education, and $110(46.8 \%)$ had university graduation.

In terms of previous duration of marriage, the minimum was 5 months, and the maximum was 336, with an average of $85.1 \pm 73.5$ months. Among the participants, $168(71.5 \%)$ were not pregnant, $17(7.2 \%)$ were less than 12 weeks pregnant, 10 (4.3) were between 12 and 24 weeks pregnant, and 35 (14.9) were between 24 and 32 weeks pregnant. Participants also expressed their love for their husbands, with 166 (70.6\%) expressing much love, 65 (27.6\%) expressing normal love, and 4 (1.7\%) expressing little love for their husband. 195 (83\%) participants got married by agreement, and another $40(17 \%)$ had an arranged marriage. Table 1 shows the general characteristics of the study population.

The FSFI questionnaire results were as follows: Desire score had an average of $2.94 \pm 1.9$, arousal score had an average of $2.97 \pm 1.32$, lubrication score had an average of $2.91 \pm 1.25$, orgasm score had an average of $3.2 \pm 1.42$. The satisfaction score had an average of $3.48 \pm 1.5$. Pain score had an average of $2.6 \pm 1.09$. Finally, the total FSFI Score had an average of $18.12 \pm 6.23$. The results of the FSFI questionnaire are shown in Table 2.

As shown in Table 2, the average total FSFI score is 18.12. Since the cut-off value for FSD is 26.0, it can be concluded that, on average, participants had poor function and quality of sexual intercourse in the previous four weeks during the lockdown. 


\begin{tabular}{|c|c|}
\hline \multicolumn{2}{|l|}{ Age [Years] } \\
\hline Average & $29.6 \pm 6.08$ \\
\hline \multicolumn{2}{|l|}{ Education } \\
\hline Primary & $10(4.3 \%)$ \\
\hline Secondary & $36(15.3 \%)$ \\
\hline High school & $79(33.6 \%)$ \\
\hline University & $110(46.8 \%)$ \\
\hline \multicolumn{2}{|l|}{ Pregnancy Status } \\
\hline Not pregnant & $168(71.5 \%)$ \\
\hline Less than 12 weeks & $17(7.2 \%)$ \\
\hline Between 12-24 weeks & $10(4.3 \%)$ \\
\hline Between 24-32 weeks & $35(14.9 \%)$ \\
\hline \multicolumn{2}{|l|}{ Income } \\
\hline Under $1500 \mathrm{TL}$ & $16(6.8 \%)$ \\
\hline $1500-3000 \mathrm{TL}$ & $86(36.6 \%)$ \\
\hline 3000-5000 TL & $84(35.7 \%)$ \\
\hline Over $5000 \mathrm{TL}$ & $49(20 \%)$ \\
\hline \multicolumn{2}{|l|}{ Marriage form } \\
\hline By agreement & $195(83 \%)$ \\
\hline Arranged & $40(17 \%)$ \\
\hline \multicolumn{2}{|l|}{ Job } \\
\hline Housewife & $130(55.3 \%)$ \\
\hline Employment & $105(44.7 \%)$ \\
\hline \multicolumn{2}{|l|}{ Affection } \\
\hline Love him a little & $4(1.7)$ \\
\hline Love him normally & $65(27.6)$ \\
\hline Love him so much & $166(70.6)$ \\
\hline
\end{tabular}

\section{Table 2. Results of the FSFI questionnaire}

\begin{tabular}{|lccccc|} 
Variable & N & Minimum & Maximum & Mean & SD \\
\hline Desire & 235 & 1 & 5 & 2.94 & 0.95 \\
Arousal & 235 & 0 & 5 & 2.97 & 1.32 \\
Lubrication & 235 & 0 & 5 & 2.91 & 1.25 \\
Orgasm & 235 & 0 & 5 & 3.2 & 1.42 \\
Satisfaction & 235 & 0 & 5 & 3.48 & 1.5 \\
Pain & 235 & 0 & 4.67 & 2.6 & 1.09 \\
Total & 235 & 1 & 26.75 & 18.12 & 6.23 \\
\hline
\end{tabular}

The results of the Kolmogorov test show that not all quantitative variables have a normal distribution. With the FSFI score classification, the respondents were divided into low and medium categories. Participants with a score of $\leq 23$ were placed in the low category, and participants with a score of $>23$ were placed into the medium category. Table 3 examines the relationship between demographic variables with the total variable using Kruskal-Wallis test. Then Table 4 examines the qualitative variables with the total variable using the Chisquare test.

The results of Table 3 showed that the values of the FSFI score are significantly different according to the age of the woman ( $p$-value $=0.003$ ), the age of the man ( $p$-value $=0.005)$, and duration of marriage ( $p$-value $=0.006)$. The results are shown in Table 3 .
Table 3. Comparing the FSFI score categories with participant characteristics

\begin{tabular}{|lccc|}
\hline & \multicolumn{2}{c}{ Total } & p-value \\
\hline Variable & Low & Medium & \\
Age of woman & $30.2(6.3)$ & $27.3(4.4)$ & 0.003 \\
Age of man & $33.5(6.4)$ & $30.5(5.3)$ & 0.005 \\
High $(\mathrm{cm})$ & $162.9(5.8)$ & $161.8(4.5)$ & 0.2 \\
Weight & $71.2(13.4)$ & $69.8(13.6)$ & 0.4 \\
Duration of marriage & $91.4(76.5)$ & $57.18(49.7)$ & 0.006 \\
\hline
\end{tabular}

\section{Table 4. Comparing the qualitative variables with the FSFI total}

\section{score}

\begin{tabular}{|c|c|c|c|}
\hline \multirow{2}{*}{ Variable } & \multicolumn{2}{|c|}{ Total } & \multirow{2}{*}{ P-value } \\
\hline & Low & Medium & \\
\hline \multicolumn{4}{|l|}{ Pregnancy } \\
\hline Not pregnant & $138(71.9)$ & $30(69.8)$ & \multirow{5}{*}{0.6} \\
\hline Less than 12 weeks & $12(6.3)$ & $5(11.5)$ & \\
\hline Between 12-24 weeks & $8(4.2)$ & $2(4.7)$ & \\
\hline Between 24-32 weeks & $29(15.1)$ & $6(14)$ & \\
\hline Not pregnant & $5(2.6)$ & 0 & \\
\hline \multicolumn{4}{|l|}{ Education } \\
\hline Primary & $9(4.7)$ & $1(2.3)$ & \multirow{4}{*}{0.7} \\
\hline Secondary & $62(32.3)$ & $17(39.5)$ & \\
\hline High school & $29(15.1)$ & $7(16.3)$ & \\
\hline University & $92(47.9)$ & $18(41.9)$ & \\
\hline \multicolumn{4}{|l|}{ Affection } \\
\hline Love him a little & $4(2.1)$ & 0 & \multirow{3}{*}{0.01} \\
\hline Love him normally & $128(66.7)$ & $38(88.4)$ & \\
\hline Love him so much & $60(31.3)$ & $5(11.6)$ & \\
\hline \multicolumn{4}{|l|}{ Job } \\
\hline Housewife & $108(56.3)$ & $22(51.2)$ & \multirow{2}{*}{0.6} \\
\hline Employment & $84(43.8)$ & $21(48.8)$ & \\
\hline \multicolumn{4}{|l|}{ Marriage form } \\
\hline By agreement & $157(81.8)$ & $38(88.4)$ & \multirow{2}{*}{0.3} \\
\hline Arranged & $35(18.2)$ & $5(11.6)$ & \\
\hline \multicolumn{4}{|l|}{ Income } \\
\hline Under $1500 \mathrm{TL}$ & $14(7.3)$ & $2(4.7)$ & \multirow{4}{*}{0.7} \\
\hline $1500-3000 \mathrm{TL}$ & $71(37)$ & $15(34.9)$ & \\
\hline $3000-5000 \mathrm{TL}$ & $66(34.4)$ & $18(41.9)$ & \\
\hline Over $5000 \mathrm{TL}$ & $41(21.4)$ & 89 (18.6) & \\
\hline
\end{tabular}

As shown in Table 4, the only factor influencing the FSFI total score of qualitative variables is the woman's affection for her husband. The correlation of participant characteristics with the total FSFI score was examined, and the results are shown in Table 5.

As shown in Table 5, the woman's age (Sig. $=0.008$ ), the man's age (Sig. $=0.004$ ), and duration of marriage (Sig. $=0.02$ ) have a significant and negative correlation with the total FSFI score. This means that the older a woman, man, and duration of marriage are, the lower the total FSFI score.

Table 5. Correlation of total FSFI score with participant characteristics

\begin{tabular}{|lcc|} 
Variable & Correlation Coefficient & Sig. \\
Age of woman & -0.17 & 0.008 \\
Age of man & -0.19 & 0.004 \\
Height $(\mathrm{cm})$ & -0.09 & 0.1 \\
Weight $(\mathrm{kg})$ & -0.03 & 0.6 \\
Duration of marriage & -0.15 & 0.02 \\
\hline
\end{tabular}


Table 6 also shows the comparison of pregnant and non-pregnant participants regarding their FSFI scores. It has been shown that there is no significant difference between the two groups regarding their FSFI score.

\begin{tabular}{|lccccc|}
\hline \multicolumn{6}{|c|}{ Table 6. Comparison of pregnant vs. non-pregnant participants } \\
\hline & Pregnancy & N & Mean & t & Sig. \\
\hline & non-pregnant & 168 & $\begin{array}{c}18.3 \\
(6.03)\end{array}$ & 0.71 & 0.4 \\
FSFI & & & & & \\
scores & pregnant & 67 & $\begin{array}{c}17.6 \\
(6.7)\end{array}$ & & \\
& & & & &
\end{tabular}

\section{DISCUSSION}

Our results showed that the overall FSFI score decreased significantly during the pandemic, which means that pandemic and lockdown had a negative impact on the women's quality of sexual life in our study. The results also showed that all six aspects of FSFI were significantly reduced among the participants. Our results were consistent with a study by Yuksel and Ozgor (15). They conducted a similar study in Turkey and found that women's quality of sexual life decreased significantly during the COVID-19 pandemic. However, their results showed that the number of intercourses and sexual desire increased during the lockdown. Their results also showed that during the COVID-19 pandemic, couples were less willing to have children (15).

One of the most important factors affecting the quality of couples' sexual health is their stress and level of anxiety (16). Hall, Kusunoki (17) studied 992 women aged 18 to 20 years and showed that stress and anxiety levels could negatively affect the quality of couples' sexual relationships. Another study by Liu Liu, Han (18) after the 2010 earthquake in Asia showed that individuals' sexual function is impaired after a natural disaster, and couples experience reduced sexual satisfaction. These results show that when bad things happen to everyone around and the level of anxiety and stress increases, sexual health quality decreases significantly $(17,18)$.

Fear of the possibility of pregnancy can be considered as one of the factors reducing the number of intercourses during the lockdown $(19,20)$. Research is currently underway to determine the effects of COVID-19 on pregnant women. Data are limited, but there is currently no evidence that pregnant women are more likely to develop the disease's severe form than the general population. However, due to physical and immune system changes in pregnant women, they can become seriously ill due to respiratory infections $(16,19)$.

Micelli, Cito (21) examined the effect of COVID-19 on Italians' decision to have children. They did not find a significant difference between the number of intercourses before and after the COVID-19 pandemic between Italian couples. More than a third of couples who decided to have children decided to postpone the decision due to the pandemic. Factors influencing this decision include economic instability and lack of knowledge about pregnancy outcomes due to the prevalence of the disease. However, this study showed that $12 \%$ of couples decided to have children during the lockdown (21).

Other studies on couples' sexual satisfaction after natural disasters such as floods and earthquakes have shown that couples' desire for sex decreases (22-24). However, Yuksel and Ozgor (15) studied couples' sexual behaviors during the COVID-19 pandemic and concluded that the number of intercourses between couples has increased. This inconsistency can be due to two reasons: first, the COVID-19 pandemic has not destroyed people's living space, unlike floods and earthquakes, and second, the couple has more free time at home. However, their results showed that despite the increase in the number of intercourses, sexual satisfaction between couples has decreased, which is consistent with our study results (15).

This is the first study to look at the relationship between women's age and sexual satisfaction during the COVID-19 pandemic. Our results show that older men and women have decreased sexual satisfaction during the COVID-19 pandemic. This decrease may be due to the higher risk of COVID-19 for older people, and therefore older people are more prone to stress than younger people.

One of the most important limitations of this study was the lack of identical pre-pandemic data for comparison with post-pandemic data. Another limitation of this study was the small number of samples. Also, the FFSI questionnaire is usually answered physically and faceto-face, but due to COVID-19 pandemic limitations, the questionnaire was emailed to participants, which could affect participants' responses. Because sexual satisfaction is a complex matter, and many factors can influence it, including male sexual behavior, future studies should consider more influencing factors.

\section{CONCLUSION}

This study showed that the COVID-19 pandemic and lockdown reduced the quality of women's sex life. This result may be due to increased anxiety and stress in women during the pandemic. Our results also show that the older women and men are, the lower their sexual satisfaction will be, which may be due to the higher risk of COVID-19 for the elderly and thus the greater the stress on them. The results obtained in this study should be supported by prospective studies and a larger number of samples. 


\section{ETHICAL DECLARATIONS}

Ethics Committee Approval: The study was approved by the Ethical Committee of Amasya University (07/05/2020-5/28 ) and the Turkish Republic dated 202005-07T15-56-23 after approval of the application for work by the Ministry of Health Scientific Research Platform.

Informed Consent: Written informed consent was obtained from all participants who participated in this study.

Referee Evaluation Process: Externally peer-reviewed.

Conflict of Interest Statement: The authors have no conflicts of interest to declare.

Financial Disclosure: The authors declared that this study has received no financial support.

Author Contributions: All of the authors declare that they have all participated in the design, execution, and analysis of the paper, and that they have approved the final version

\section{REFERENCES}

1. Ge H, Wang X, Yuan X, et al. The epidemiology and clinical information about COVID-19. Eur J Clin Microbiol Infect Dis 2020: 1 .

2. Lai CC, Shih TP, Ko WC, Tang HJ, Hsueh PR. Severe acute respiratory syndrome coronavirus 2 (SARS-CoV-2) and corona virus disease-2019 (COVID-19): the epidemic and the challenges. Int J Antimicrob Agents 2020: 105924.

3. Lauer SA, Grantz KH, Bi Q, et al. The incubation period of coronavirus disease 2019 (COVID-19) from publicly reported confirmed cases: estimation and application. Ann Intern Med 2020; 172: 577-82

4. Li G, Tang D, Song B, et al. Impact of the COVID-19 pandemic on partner relationships and sexual and reproductive health: cross-sectional, online survey study. J Med Internet Res 2020; 22 e20961.

5. Pedrozo-Pupo JC, Pedrozo-Cortés MJ, Campo-Arias A. Perceived stress associated with COVID-19 epidemic in Colombia: an online survey. Cadernos de Saúde Pública 2020; 36: e00090520.

6. Ventriglio A, Bhugra D. Sexuality in the 21st century: Sexual fluidity. East Asian Arch Psychiatry 2019; 29: 30.

7. Karli P, Kara OF. Is tubal ligation effective on sexual dysfunction? Medical Science and Discovery 2019; 5: 180-4.

8. Chen $\mathrm{CH}$, Lin YC, Chiu LH, et al. Female sexual dysfunction: Definition, classification, and debates. Taiwan J Obstet Gynecol 2013; 52: 3-7.

9. Anastasiadis AG, Davis AR, Ghafar MA, Burchardt M, Shabsigh $R$. The epidemiology and definition of female sexual disorders. World J Urol 2002; 20: 74-8.

10. Geiss I, Umek W, Dungl A, Sam C, Riss P, Hanzal E. Prevalence of female sexual dysfunction in gynecologic and urogynecologic patients according to the international consensus classification. Urology 2003; 62: 514-8.

11. Raina R, Pahlajani G, Khan S, Gupta S, Agarwal A, Zippe CD Female sexual dysfunction: classification, pathophysiology, and management. Fertil Steril 2007; 88: 1273-84.

12. Stephenson KR, Toorabally N, Lyons L, M. Meston C. Further validation of the Female Sexual Function Index: specificity and associations with clinical interview data. J Sex Marital Ther 2016; 42: 448-61.
13. Meston CM, Freihart BK, Handy AB, Kilimnik CD, Rosen RC. Scoring and Interpretation of the FSFI: What can be Learned From 20 Years of use? J Sex Med 2020; 17: 17-25.

14. Meston CM, Kilimnik CD, Freihart BK, Buss DM. Why Humans Have Sex: Development and Psychometric Assessment of a Short-Form Version of the YSEX? Instrument. J Sex Marital Ther 2020; 46: 141-59.

15. Yuksel B, Ozgor F. Effect of the COVID-19 pandemic on female sexual behavior. Int J Gynecol Obstet 2020

16. Dashraath P, Jeslyn WJL, Karen LMX, et al. Coronavirus disease 2019 (COVID-19) pandemic and pregnancy. Am J Obstet Gynecol 2020.

17. Hall KS, Kusunoki Y, Gatny H, Barber J. Stress symptoms and frequency of sexual intercourse among young women. J Sex Med 2014; 11: 1982-90.

18. Liu S, Han J, Xiao D, Ma C, Chen B. A report on the reproductive health of women after the massive 2008 Wenchuan earthquake. Int J Gynecol Obstet 2010; 108: 161-4.

19. Hollander JE, Carr BG. Virtually perfect? Telemedicine for COVID-19. N Engl J Med 2020; 382: 1679-81

20. Lee HH, Lee PR, Kao WT, Lee YL. The relationship between sex life satisfaction and job stress of married nurses. BMC Res Notes 2012; 5: 445.

21. Micelli E, Cito G, Cocci A, et al. Desire for parenthood at the time of COVID-19 pandemic: an insight into the Italian situation. J Psychosom Obstet Gynaecol 2020: 1-8.

22. Rowland DL, Kolba TN. Relationship of specific sexual activities to orgasmic latency, pleasure, and difficulty during partnered sex. J Sex Med 2019; 16: 559-68.

23. Stavdal MN, Skjævestad MLL, Dahl B. First-time parents' experiences of proximity and intimacy after childbirth-A qualitative study. Sex Reprod Healthc 2019; 20: 66-71.

24. Zhang H, Liu T, Zhou Z, et al. miR-137 affects vaginal lubrication in female sexual dysfunction by targeting aquaporin-2. Sex Med 2018; 6: 339-47. 